\section{Ciproterone Effect on Compulsive Masturbation in a Frontotemporal Dementia Patient}

\section{To the Editor: Frontotemporal} dementia results from frontal and anterior temporal cortical degeneration, leading to prominent behavioral changes, with severe disruption of personality and social abilities. ${ }^{1}$ Among those are several well-known impulse-control disorders. Herein we present the therapeutic approach used in a frontotemporal dementia male patient with compulsive masturbation.

\section{Case Report}

A 75-year-old man, without previous known diseases or family history of dementia, was seen for slowly progressive behavioral changes. Over the previous 4 years, he insidiously started being sexually uninhibited, making proposals to all women, including his own daughter, and irresistible masturbating several times a day. He also developed many other behavioral features like excessive food intake, complete hygiene neglect, garbage collecting, and compulsive cigarette smoking, averaging three packs a day. At the time of our first evaluation the main symptom was clearly the compulsive masturbation, which he did at least eight times a day. This was also the most disruptive symptom to his wife, with whom he did not have sexual intercourse over the preceding years. Neuropsychological study showed severe dysfunction in all frontal lobe-directed tests, and brain MRI revealed frontotemporal atrophy; the PET scan showed hypometabolism on the same location. Sertraline, $100 \mathrm{mg} /$ day, led to some symptomatic relief in all nonsexual symptoms. Quetiapine was then added and increased until a $400 \mathrm{mg}$ daily dose was reached. The effect on the masturbatory acts was only slight, with the patient still doing them five to six times daily. Ciproterone (50 mg/day) was then prescribed, with complete resolution of this particular behavior, an effect sustained over the 6-month available follow-up without any reported side effects. Curiously, cigarette smoking was not at all affected.

\section{Discussion}

The frontal lobes, mainly their orbitofrontal region, seem to have a significant role in impulse-control over the motor aspects of human sexuality. ${ }^{2}$ This is supported by several findings of inappropriate sexual behaviors, including automatisms, in patients with frontal lobe pathology, the best known being those after leucotomy and in partial epilepsies. $^{2}$

Most symptoms presented by our patient were previously reported in frontotemporal dementia, except the compulsive masturbation, which is exceedingly rare in dementia patients and, to our knowledge, not elsewhere reported in this specific dementia syndrome. Nevertheless, a 90-year-old Alzheimer's disease patient, who repeat- edly inserted foreign bodies in the urethra with masturbatory purposes, was reported. ${ }^{3}$

Treatment of inappropriate sexual behaviors of patients with dementia is largely unknown. By promoting incomplete suppression of testosterone levels, ciproterone and other progesterone-based compounds with anti-androgenic properties have been shown to reduce sexual activity in patients with dementia, ${ }^{4}$ without significant side effects. This suggests it can be a useful first-line option in this unusual disruptive behavior.

Luís FonseCA, M.D.

Sónia Simões, M.D.

PATrício Ferreira, M.D.

Joana Mesquita, M.D.

Psychiatry and Mental Health

Department, Hospital São

Marcos, Braga, Portugal

Álvaro Machado, M.D.

Neurology Department, Hospital São Marcos, Braga, Portugal

\section{References}

1. Neary D, Snowden J, Mann D: Frontotemporal dementia. Lancet Neurol 2005; 4:771-780

2. Baird AD, Wilson SJ, Bladin PF, et al: Neurological control of human sexual behavior: insights from lesion studies. J Neurol Neurosurg Psychiatry 2007; 78:1042-1049

3. Rosenthal M, Berkman P, Shapira A, et al: Urethral masturbation and sexual disinhibition in dementia: a case report. Isr J Psychiatry Relat Sci 2003; 40:67-72

4. Haussermann P, Goecker D, Beier K, Schroeder S: Low-dose cyproterone acetate treatment of sexual acting out in men with dementia. Int Psychogeriatr 2003; 15:181-186 